\title{
UNA COMPRENSIÓN HISTÓRICA DE LA CIENCIA
}

\author{
HISTORICAL UNDERSTANDING OF SCIENCE
}

Richard Antonio Orozco C.*

\begin{abstract}
RESUMEN
En este breve ensayo, el autor va explicando con algún detalle la formación de la ciencia a partir de la comprensión que la epistemología hace de ella. Recorre, sin embargo, solo cuatro momentos claves: su formación, la revolución moderna, el cientificismo del siglo XIX y finalmente, la comprensión realizada por la epistemología contemporánea. El autor escoge estos momentos, no por arbitrariedad, sino porque los considera realmente significativos para entender lo que es la ciencia en la actualidad.
\end{abstract}

\section{PALABRAS CLAVES}

Ciencia, Epistemología, Historia de la ciencia, Cientificismo.

\begin{abstract}
In this brief essay, the author will explain in some detail the formation of science from understanding that epistemology makes it. He sees, however, only four key moments: their formation, the modern revolution, the scientism of the nineteenth century, and finally the contemporary epistemology. The author chooses this moment, not arbitrary, but because they are considered really significant to understand what science is today.
\end{abstract}

\section{KEY WORDS}

Science, Epistemology, History of Science, Scientificism.

* Docente de la Universidad Femenina del Sagrado Corazón y de la Universidad Nacional Mayor de San Marcos: richardorozcoc@unife.pe 
La filosofía de la ciencia es una mirada reflexiva y crítica de la institución que llamamos ciencia y de todo su significado para el mundo moderno. El aporte de la filosofía de la ciencia para la sociedad es indiscutible, por cuanto es innegable que el desarrollo de la sociedad depende en gran parte del desarrollo de la ciencia. Así pues, comprender la manera en la que se producen los conocimientos científicos o reconocer en ellos su real dimensión (superando ingenuidades y subestimaciones) viene a ser una acción directa y concreta que permite a la sociedad encaminarse hacia los objetivos que ella misma se pueda plantear. Solo en la medida en que la sociedad es consciente de sus reales posibilidades ella podrá hacer uso de sus herramientas y creaciones de manera más eficiente e intencionada.

La comprensión de la ciencia puede asumir distintas perspectivas de trabajo. Se puede comprender la manera en la que se practica la ciencia, o se puede realizar una comprensión de las relaciones entre la ciencia y la sociedad. Se puede discutir sobre la verdad que alcanza la labor científica o se puede reflexionar sobre las principales características del conocimiento científico. En este ensayo, queremos plantearnos una comprensión de la ciencia desde una perspectiva histórica. Comenzaremos tratando de entender el origen de la ciencia en el mundo griego (1); luego nos ocuparemos del surgimiento de la ciencia moderna, que viene a ser el momento en que la ciencia se separó de la filosofía (2); procuraremos luego una comprensión del positivismo decimonónico y su sobreexaltación de las posibilidades de la ciencia, lo que en términos conceptuales llamamos cientificismo (3). Finalmente, revisaremos someramente la comprensión de la ciencia que nos han presentado dos de los más importantes epistemólogos del siglo
XX, Karl Popper y Thomas Kuhn, y que han procurado responder a las nuevas expectativas de la ciencia a partir del derrumbe de la física newtoniana (4).

\section{El nacimiento de la ciencia y la filosofía en el mundo griego.}

Evandro Agazzi afirma que la ciencia es "el trazo más distintivo de occidente", (2011) su aventura más espléndida. Incluso su afirmación es más audaz pues sostiene que ninguna otra cultura puede mostrar un logro parecido. Si esta afirmación es discutible en la implícita comparación entre occidente y las otras "culturas", no así lo es al sostener a la ciencia como el "alma de occidente". Casi podríamos decir con certeza, occidente nació cuando nació la ciencia.

El nacimiento de la ciencia se remonta al siglo V antes de Cristo. Ese momento histórico es entendido como el paso del MITO al LOGOS. Supuso una premisa fundamental: la naturaleza es cognoscible; es decir, se superó el carácter azaroso y caótico de la naturaleza que era hasta ese momento dependiente de la voluntad pasional de los dioses, para entenderla luego, a partir del LOGOS, desde sus regularidades y principios racionales. La pregunta que dio origen a toda esta revolución fue la escéptica que dice cy si todas estas regularidades explican completamente a la naturaleza sin suponer la existencia de los dioses? ¿y si las enfermedades y terremotos no son causadas por dioses, sino por causas completamente naturales? Si la naturaleza es cognoscible, entonces la razón humana (LOGOS) tiene acceso a ella.

Este pues fue el origen de la ciencia y la filosofía. Ellas, en un primer momento, no se encontraban diferenciadas; y podemos añadir además que no solo ambas nacieron juntas sino que también con ellas 
apareció la democracia, entendida esta como crítica y discusión. La aparición de la ciencia y la filosofía supuso la superación del MITO como respuesta satisfactoria a la curiosidad intelectual, característica intrínseca al espíritu humano. Pero, ¿cómo el MITO perdió el carácter satisfactorio que poseía? En la respuesta a esta pregunta está también la defensa de mi afirmación de que la ciencia y la filosofía nacieron junto a la democracia. El MITO pierde el carácter satisfactorio cuando apareció la crítica escéptica. No es gratuito que esto haya sucedido en Grecia, una esquina de Europa que por sus características territoriales podría haber pasado desapercibida. Los especialistas reconocen que el carácter mercantil de Grecia, la condición de ser esquina obligada de paso de mercaderes en diferentes rutas, la hizo apropiada para el surgimiento del espíritu crítico escéptico. No hubiese sido posible que dicho espíritu hubiese aparecido con tal fuerza y presencia en tradiciones sólidas y más enraizadas como las de las grandes culturas. En Grecia, en cambio, fue posible la pregunta escéptica: si el Dios Marduk babilónico y el dios Zeus Griego cumplen roles idénticos en la creación del universo ¿no podría alguno de ellos ser inventado? Y si así era, ¿jpor qué no ambos? Grecia era un lugar de encuentro entre mercaderes y tradiciones. La diversidad fomenta la duda escéptica. Algunas veces se afirma que la actitud de los griegos es caracterizada por esa disposición hacia escuchar toda idea nueva. Un buen ejemplo de ello es el pasaje bíblico que narra el viaje de Pablo a Atenas y en donde se afirma que los griegos no encontraban mejor forma de pasar el tiempo que explorando nuevas ideas (Hechos 17); pero no es claro si esta es la causa o más bien es el efecto. Lo cierto es que en Grecia se forjó la libertad necesaria para superar el MITO y dar paso a una posible explicación de la naturaleza que no tenga necesidad de recurrir a seres sobrenaturales (me cuido de no afirmar inmanencia plena pues aún la metafísica procurará una respuesta dirigida hacia la trascendencia).Lo más importante para nosotros es que aquí, cuando nació la ciencia y la filosofía, nació también occidente y por eso Agazzi puede sostener que esta, la ciencia, es el alma de occidente.

Habría que considerar tres características importantes de la ciencia en estos momentos iniciales. En primer lugar, la ciencia es aquí un saber. Esto significa que una persona posee ciencia en la medida que es capaz de dar razones (ofrecer una demostración argumentativa) de aquello que se conoce. La importancia de la lógica radica en que dicha demostración exige una estructura lógica y, más específicamente, deductiva. No saber dar razones es no poseer ciencia. En segundo lugar, la ciencia constituye todo el conjunto del saber. Esto significa que los tipos de saber en pleno son ciencia, no solo alguna región de este. Así Aristóteles reconocía tres tipos de saber, el saber teorético (la matemática, la física y la metafísica), el saber práctico (ética y política) y saber poiético (las artes). La visión pues de la racionalidad para el mundo griego era muchísimo más abarcante que la que defenderán los modernos. La última característica a considerar sería que dicho saber estaba asociado no a la gente productiva de la sociedad, sino a la gente más ociosa de entre ellos. John Dewey nos informa de una distribución de las clases sociales en la Grecia antigua. Esta, dice Dewey, se podría entender como reducida a dos clases sociales: los hombres de la necesidad y los hombres de la libertad (Dewey, 1970). Los hombres de la necesidad son aquellos privados de la ciudadanía plena, quienes no participan de las discusiones en el Ágora y quienes tienen que realizar actividades en función 
de sus necesidades. Son las personas privadas del ocio. Los hombres de la libertad en cambio son los que gozan del privilegio del ocio. Sus actividades son gratuitas, no exigidas ni pretenden algún propósito necesario. Sus actividades son guiadas por la libertad (por puro "amor"). Es interesante que dicha descripción de Dewey coincida con la que presenta Hannah Arendt cuando nos explica el tipo de actividades del hombre griego. Arendt usa para ello los conceptos de privadopúblico, pero luego hace coincidir esta dicotomía con la de necesidad-libertad (Arendt, 2004). La ciencia aquí es realizada y es propia de los hombres de la libertad, pues ella no se guía por ningún tipo de urgencia e interés.

Sin pretender ningún tipo de menosprecio hacia la ciencia realizada por los hombres medievales, quienes ya se encontraban condicionados por la presencia del cristianismo, debemos decir que nada que pueda significar un cambio importante en la comprensión de la ciencia sucedió a lo largo de todo el Medioevo. No significa que no se haya hecho ciencia, sino más bien que el modelo de hacer ciencia se mantuvo básicamente idéntico al modelo heredado de la tradición griega. Si hiciéramos una historia de la filosofía pudiera ser necesario considerar algunos hechos y personajes relevantes, ineludibles, pero para la comprensión de la ciencia es posible pasar de largo hasta la llegada del Renacimiento. Es posible, válido y hasta importante tratar de comprender históricamente la llegada del Renacimiento desde sus raíces en el Medioevo - desde la creación de las universidades, la llegada de los textos aristotélicos a occidente o de figuras como Guillermo de Ockham - más para los propósitos de esta presentación bastará centrarnos en las figuras del Renacimiento.

\section{El origen de la ciencia moderna y su disociación de la filosofía.}

Agazzi menciona cuatro características de la revolución renacentista e indica que dependiendo de los autores cada uno ha enfatizado o uno u otro. Estas son: la crítica a la física aristotélica, la difusión de un espíritu naturalista, el abandono de la metodología deductiva y la adopción de instrumentos matemáticos en la indagación de los aspectos cuantitativos de la naturaleza, en desmedro de los aspectos cualitativos. Podríamos nosotros incluir otros tantos de índole social la secularización, el espíritu crítico, la exaltación de la aventura, el humanismo, etc. - pero aun así quedarnos con la sensación de insatisfacción; y es que quizá lo que debemos hacer es comprender que el proceso que generó la revolución renacentista es como tal un proceso multifacético y bastante complejo.

En este intento de comprender tal revolución desde el enfoque de proceso, me es pertinente hacer referencia a cuatro personajes quienes, dispersados entre los siglos XVI y XVIII, lograron desarrollar los aspectos más importantes de lo que hoy conocemos como ciencia moderna. Me refiero especificamente a Francis Bacon, Galileo Galilei, René Descartes e Inmanuel Kant. Del primero de ellos, Bacon, debemos resaltar dos ideas que él intentó desarrollar y defender aunque con poco arsenal metodológico y con más intuición filosófica. Estas fueron, en primer lugar, la necesidad de asumir el método inductivo como la única forma de hacer ciencia, y en segundo lugar, la necesidad de mantener un cuidado especial para que la ciencia pueda ser un poder que nos permita un dominio sobre la naturaleza y no sobre los hombres (pseudo-ciencia). La deducción - método que Aristóteles había planteado como propio para la ciencia - era un método que solo permitía 
dar vueltas sobre los conocimientos ya conocidos. Frente a este se encontraba la inducción que era más bien "un método para el descubrimiento". Pero también era consciente Bacon de la dificultad que entraña la inducción. Esta, entendida como "enumeración simple" es un método infantil que no puede servir para lograr una ciencia madura y firme (Bacon, 2011). Si la ciencia se queda con la inducción por enumeración simple se vuelve precaria $\mathrm{y}$, a la larga, puede derrumbarse con facilidad. "Por enumeración simple" significa ir acumulando datos a partir de las experiencias particulares. Esa acumulación nunca podría ser definitiva porque siempre estaría abierta a ser refutada con un nuevo ejemplo. De esa forma, cualquier afirmación general sobre la experiencia sería un vicio lógico, una pura generalización. En cambio, Bacon propone "la nueva inducción" que él define como "avanzar por medio de negaciones y refutaciones" hasta encontrar una afirmación cada vez más rigurosa de la naturaleza. El problema que Bacon está tratando de resolver es conjugar la necesidad de mantener a la ciencia muy junta a los datos de la experiencia, pero al mismo tiempo no caer en la fragilidad de la generalización de esos datos. La nueva inducción propuesta, en cambio, se queda junto a la experiencia, pero avanza con paso más firme pues no afirma propiamente nada, sino que niega y rechaza. Estas negaciones y rechazos hacen de las conclusiones explicaciones más sólidas acerca de la naturaleza.

La siguiente idea defendida por Bacon es la necesaria claridad de los objetivos que se plantea la ciencia. Dicha claridad está pensada desde la superación de las posibles distorsiones en su encuentro con la verdad. La búsqueda de la verdad es para Bacon un camino de encuentro con la naturaleza y las posibles distorsiones son más bien caminos de encuentros con lo que él llama ídolos. Cuatro son los tipos de ídolos que enturbian el encuentro con la verdad - ídolos de la Tribu, ídolos de la Caverna, ídolos del Foro e ídolos del Teatro. Todos estos tipos de ídolos distorsionan a la manera que las idolatrías distorsionan la auténtica devoción.

El segundo autor de quien me gustaría comentar es Galileo Galilei. En la comprensión de la ciencia moderna habría que considerar como relevantes cuatro ideas que desarrolla Galileo y que de alguna forma se convierten en rasgos principales de la nueva ciencia. En primer lugar, la superación de la ciencia entendida esta como búsqueda de las esencias. Según Galileo, buscar las esencias puede ser una tarea no solo imposible sino hasta inútil. Por el contrario, la tarea que debe acometer la nueva ciencia es "dar noticia de las afecciones" de la naturaleza. Por afecciones habría que entender accidentes aristotélicos $\mathrm{O}$, más contemporáneamente, características y relaciones de los objetos de estudio. Esta idea es ya, por sí misma, una idea revolucionaria; pues la ciencia en el mundo antiguo y medieval se encontraba centrada en la búsqueda de las esencias. Para Galileo, este "dar noticia de las afecciones" era realmente científico si se hacía en un lenguaje riguroso y racional, y este no podía ser otro que el lenguaje matemático. Esta era la segunda idea que quería comentar. Galileo ensalza el lenguaje matemático pues reconoce que el libro de la naturaleza puede ser leído en claves matemáticas. Sabe Galileo que gran parte del libro queda sin leer, pero esa parte puede ser considerada innecesaria para la comprensión plena de la naturaleza, ya que esa parte está plagada de subjetividad y equivocidad. Las características matematizables de la naturaleza serán así las características primarias.

La tercera idea a considerar es que la demostración del saber científico por 
parte de Galileo se hace ahora a través de la experimentación. Si en el mundo griego dicha demostración partía de principios metafísicos y se desarrollaba de manera deductiva, para el renacimiento en cambio tal demostración debe ser entendida como una prueba experimental o un dato empírico. Por último, la cuarta idea que hay que resaltar es la necesidad de repotenciar la información sensible para hacerla efectiva a la labor científica. Si en el mundo antiguo la información de los sentidos ha sido menospreciada, para Galileo esta en cambio debe ser repotenciada hasta convertirla en un dato científico. La repotenciación significaba reconocer que la información sensible puede ser muy equívoca y puede conducir al error (como en el caso de nuestra visión inocente del sol girando alrededor de la Tierra); pero si dicha información sensible está controlada y validada, y además es parte de una teoría a la que debe apoyar con su afirmación o con su negación, entonces dicha información sensible puede convertirse en un dato científico. Además del control y la validación, y la pertenencia a una teoría, la repotenciación de la información sensible también puede entenderse a partir del uso de instrumentos. La defensa del Heliocentrismo por parte de Galileo es una muestra clara de cómo la información sensible (en este nuevo sentido repotenciado) fue de gran utilidad para la teoría. Entender aquí la nueva comprensión de la observación (y de toda información sensible) que está presentando Galileo nos es útil para entender luego, de manera más precisa, la defensa de la observación que harán los positivistas y Augusto Comte principalmente. Ya desde Galileo se entiende que la observación puede ser comprendida desde distintos niveles y en diferentes sentidos de utilidad. El sentido común actual - muy positivista en algunos sentidos, pero muy simplón en otros - pasa por alto esta precisión y mal entiende fácilmente la ciencia y su actividad.

A parte de estas cuatro ideas que Galileo defiende y que nos muestras rasgos importantes de lo que llamamos ciencia moderna, hay que resaltar también el nuevo rol que ocupa la mecánica para el sistema de las ciencias. Galileo y sus investigaciones ha catapultado a esta rama de la física. A partir de aquí, lo que se conozca como ciencia será modelada a partir de la forma de trabajo y el tipo de respuesta que se usa en la mecánica. Es decir, el trabajo científico debe comenzar por precisar los objetos sobre los cuales se investiga para luego explicar sus características y relaciones a partir de causas y efectos o de fuerzas que interrelacionan a dichos objetos. Tal será la acogida que recibirá este nuevo modelo de labor científica que se extenderá la idea de que conocer el mecanismo de algo es eliminar su misterio, lo que también significa asumir de manera tajante una distancia con la especulación tanto metafísica como religiosa.

El siguiente autor a quien quiero comentar es René Descartes. De él solo quiero resaltar una idea que, sin embargo, pudo no haberla defendido explícitamente sino que más bien tendríamos que decir fue consecuencia de su filosofía. Me estoy refiriendo al dualismo cartesiano. Descartes defendió la idea del dualismo, pero su defensa era para sostener un espacio propio para el desarrollo de la ciencia que sería la mente (el alma la llamó él). Sin embargo, la herencia que ha llegado de él no es que la mente sea el espacio propio de la ciencia, sino todo lo contrario. El dualismo cartesiano ha permitido defender la idea de un mundo material ajeno plenamente a las confusiones de la psique lo que, junto a la mecánica ensalzada por Galileo, 
ha permitido el desarrollo y defensa del materialismo en los dos siglos posteriores. Lo que Descartes defendió fue la separación plena entre lo material (res extensa) y lo espiritual (res cogitans) no defendió un materialismo científico; mas el dualismo categórico ha sido usado como fuente teórica para la defensa de posiciones materialistas y para el cientificismo del siglo XIX. Que la materia pueda ser conocida por sí misma y que se le despoje completamente de todo sentido de finalidad (telos) son premisas importantes en el desarrollo de la ciencia moderna.

Finalmente, aunque no menos importante, nos toca tratar el aporte de Inmanuel Kant a la forja de la ciencia moderna. Voy a considerar específicamente un aporte de Kant. Me refiero a la importancia de trabajar con una hipótesis. Kant no lo desarrolla con ese concepto, pero sus ideas defendidas en la Crítica de la razón pura pueden mostrarnos una defensa del método hipotético deductivo. Lo que Kant defiende es una nueva forma de entender la ciencia en una sociedad ilustrada. El concepto que Kant usa no es el de sociedad ilustrada ni ciencia moderna, sino más bien "el camino seguro de la ciencia" (Kant, 1988). Kant quiere mostrarnos y explicarnos qué disciplinas y cómo han logrado el camino seguro de la ciencia. Nos propone como ejemplo la lógica, la matemática y la física. Especialmente en los dos últimos, la explicación es clara: estas disciplinas han logrado ese camino seguro porque han asumido una nueva actitud para el científico enfrentado a la naturaleza. El científico pre-ilustrado espera, es dependiente de la naturaleza, metafóricamente hablando, se acomoda a la naturaleza. El científico ilustrado, en cambio, se adelanta a la naturaleza con sus pensamientos (hipótesis) y obliga a la naturaleza a responder a sus preguntas "ya no a manera de un discípulo que escucha a su maestro, sino a la manera de un juez autorizado que interroga al testigo con sus preguntas". Esta idea de acercarse a la naturaleza con nuestros propios planteamientos no pretende defender la idea griega de iniciar la labor científica con premisas metafísicas, sino que más bien se trata de comenzar a hacer ciencia sobre la base de respuestas o ideas que deben ser refutadas o validadas por la experiencia (el encuentro con la naturaleza). Kant afirma que el científico hace ciencia llevando en una mano sus propios planteamientos y en la otra su experiencia. Esto es, según Kant, lo que hace que el científico cambié de actitud, ya no es él quien se acomoda a la naturaleza, sino que "son los objetos los que se acomodan a él".

Vemos así pues que Bacon, Galileo, Descartes y Kant han bosquejado las directrices principales sobre las cuales entender lo que llamamos ciencia moderna. Resumiendo sería un trabajo que parte de una hipótesis, que se desarrolla intentando sostener o rechazar dicha hipótesis pero a partir de experimentos; que dichos experimentos se realizan con el uso de instrumentos y controlando y validando las informaciones sensibles; que el método que se usa es el método inductivo; que para mantener la rigurosidad de la respuesta toda esta explicación se desarrolla en claves matemáticas; que las respuestas finales de dicha investigación nos debe llevar a entender el mecanismo que funciona tras el objeto de estudio y que tal explicación pretende ser completamente material $\mathrm{y}$, por lo mismo, objetivo y ajeno de las confusiones de la psique. Así entendida la ciencia moderna podremos entender mejor el siguiente paso de la historia de la ciencia que viene a ser el cientificismo del siglo XIX que podemos definirlo como la sobreestimación de la ciencia y sus posibilidades. 


\section{La sobreestimación de la ciencia: el cientificismo del siglo XIX.}

La filosofía kantiana sobre la ciencia bien puede considerarse una consagración de la ciencia moderna como el paradigma de la racionalidad y el saber. Con Kant es posible afirmar que el modelo de ciencia newtoniano se presenta como la nueva y única forma de hacer ciencia. La pregunta de Kant no era cómo es posible la ciencia, sino que su pregunta era: si la ciencia de Newton es exitosa, pues consigue dar leyes partiendo de las informaciones de la experiencia; entonces, ¿cómo es posible ello?, o ccuál es la teoría del conocimiento que define esa manera de hacer ciencia? El resultado de dicha pregunta es la solución a la larga discusión entre racionalistas y empiristas. Como diría Kant, es posible hacer ciencia - a la manera en que Newton lo hace - porque se construye el conocimiento partiendo de dos fuentes: la razón a priori y la experiencia.

No obstante, definir al modelo de Newton como el paradigma de ciencia es también asumir un sesgo con las fortalezas y debilidades que esto supone; sesgo del cual no fuimos conscientes sino hasta ya entrado el siglo XX. El paradigma de Newton era la mecánica y esto significaba necesariamente una reducción en la forma de entender la naturaleza. Gran parte de la crítica a la "modernidad" que se desarrolló en el último medio siglo está dirigida hacia dicho reduccionismo. Desde el paradigma de la complejidad, - otra forma de plantear la investigación científica - el paradigma newtoniano es concebido como una explicación "en forma cuantitativa [de] los movimientos de toda la materia al considerar los objetos como puntos en el espacio sujetos a fuerzas. Así, se hizo una descripción maravillosa del movimiento de la Tierra alrededor del sol... En general, los movimientos del Sol, la Tierra, una manzana, así como un átomo y una galaxia podían predecirse al abstraerlo a puntos infinitesimales de materia" (Earls, 2013, p. 12).

El programa de ciencia newtoniana consideraba tres pasos a seguir: 1) identificar elementos o componentes, 2) especificar las propiedades de dichos elementos; y 3) determinar el "mecanismo" que gobierna sus movimientos. Como dijimos, tal programa había mostrado lo exitoso que podía ser superando con creces el modelo de la ciencia trabajado en la Escolástica o el modelo de la ciencia de raíces aristotélicas. El mecanismo era la superación del misterio y, además, por su carácter cuantificable, era claramente superior en su rigurosidad y precisión. Muy pronto, inteligencia se volvió sinónimo de cálculo; y "máquina" fue el modelo para entender incluso al ser humano y al animal. Es en Descartes en donde podemos encontrar este argumento del animal máquina. La idea de mostrar "el mecanismo" de los instintos en el animal termina con las soluciones metafísicas a la pregunta que plantea la comprensión del animal y el ser humano.

La máquina, además, está unida a las matemáticas y a la plenitud de la comprensión que puede dar el lenguaje formal matemático. Prueba de esto es también la explicación de la ética que realiza Baruch Espinoza, quien culmina cada afirmación ética con la satisfacción de haber logrado una demostración geométrica que verdaderamente dé por terminada la discusión y la especulación.

Todo este enfoque que privilegiaba a la máquina y al mecanismo como modelo de investigación no solo estaba asentado en el éxito de la ciencia newtoniana, sino también en la aparición exitosa de nuevas disciplinas, así como también de las transformaciones sociales generadas por la revolución industrial y que eran interpretadas como favorables para el 
ser humano. Sobre las nuevas disciplinas que ingresan de manera exitosa a la cultura habría que considerar, en primer lugar, a la química. Esta había deambulado por la cultura medieval con un sesgo medio mágico que la unía más bien a lo esotérico. La superación de la alquimia por parte de la química significaba también la superación de ese aire mágico esotérico a favor de una disciplina científica entendida esta como una explicación material y mecánica de los cuerpos. Se trataba ahora de reconocer elementos, propiedades y transformaciones racionalizables (explicables racionalmente) de los cuerpos. El mejor ejemplo de dicho nuevo estado significó la publicación de libro El químico escéptico, en 1661 por parte de Robert Boyle. La química se estaba convirtiendo así en una ciencia de experimentos y observaciones como titula un libro de Georg Stahl de 1731 - pero también por la manera en la que Kant y otros miembros prominentes de la cultura la estaban reconociendo: casi indistinguible de la física. ${ }^{1}$ No obstante, la principal revolución de la química vino de la mano de un tercer personaje: Antoine Lavoisier, quien en 1772 daba por terminada la hipótesis del flogisto presentando en la academia de París una nueva hipótesis que explica la calcinación y la reducción a partir de un nuevo elemento: el oxígeno. Como dice Agazzi, "la estricta observación del método experimental, instrumental y cuantitativo se iba mostrando como el nuevo fundamento epistemológico de la química". (Agazzi, 2011, p. 107) Lo importante aquí es resaltar que la química no nació aislada de la "cultura científica" de la época, al contrario, nació muy dependiente del modelo mecanicista de la física, prueba de ello es que el rol fundamental de la nueva ciencia lo cumplen tanto "el elemento químico" como "la ley de conservación de la materia". La explicación vía elementospropiedades era el modelo que la química estaba siguiendo.

La discusión entre el vitalismo y el mecanicismo (entre quienes afirman un origen distinto para la vida y quienes niegan esa respuesta por considerarla religiosa o metafísica), el rejuvenecer de la biología a partir de los experimentos y las hipótesis, así como los encuentros entre la química y la biología - la química orgánica - son componentes importantes que nos ayudan a entender el clima científico cultural de la época.

Mas, debemos considerar un elemento cultural-sociológico de suma importancia que ayuda a explicar cómo se forjó nuestra modernidad: la revolución industrial. La vertiginosa aparición de inventos y artefactos fueron modelando una nueva forma de sociedad y de transacciones económicas. Primero, a partir del uso del carbón para más adelante asumir el uso del petróleo y la electricidad. Las sociedades entonces vieron surgir los "opificios" (factorías) y las manufacturas. El nuevo orden social se asentó en el capital, en la parcelación del trabajo y en la propiedad privada; generando así nuevos personajes que explicaban de manera distinta la producción y el desarrollo (capitalista, empleado, obrero, etc.). Pero la revolución industrial no solo era vista como transformación del orden social (fue su lado más criticado, especialmente por el marxismo y por la Doctrina Social de la Iglesia) sino que también era vista como fuente de desarrollo. Los inventos

1 Hay que hacer notar que Kant identifica a Stahl junto a Galileo y a Torricelli como modelos de la física que ha alcanzado "el seguro camino de la ciencia". Cfr. "Prólogo a la segunda edición". (Kant, 1988) 
industriales eran vistos como una nueva forma de comodidad y eficacia. Además, el avance de la medicina y de la farmacología estaba muy unido al progreso de la técnica y del uso de los instrumentos científicos. Las epidemias podían ser combatidas gracias a los antibióticos - Louis Pasteur y Robert Koch fueron pioneros en esto - y se garantizaba así una mayor expectativa de vida.

El elemento cultural-filosófico que habría que considerar junto a estos que estamos comentando es la nueva noción de "progreso". En la antigüedad - como se puede ver en gran parte de los mitos fundacionales de estas - el estado de bienestar y felicidad se hallaba principalmente asentada en los orígenes. El camino de búsqueda de dicho estado de bienestar y felicidad era, de esta forma, un "retorno a los orígenes". La noción de progreso como un camino hacia un mundo mejor - porque se puede aprender del pasado y, utilizando dicho aprendizaje, hacer que el futuro se muestre más beneficioso - es recién aparecida con la revolución industrial y con todo el discurso racionalista y emancipista del siglo de la luces. El futuro se torna mejor y las posibilidades son variadas, así lo entiende el hombre europeo del siglo XIX. La tecnología promovía producción a niveles jamás pensados - el desarrollo del transporte y el uso de artefactos - al punto de multiplicar por decenas las bodegas de almacenamiento. Solo en Inglaterra, la producción de algodón creció en pocas décadas (a comienzos del siglo XIX) en doce veces lo que había conseguido en las últimas décadas del anterior siglo. Las mismas universidades promovían ese nuevo espíritu progresista. El modelo de la universidad alemana se expandió por todo el continente, y este modelo estaba asentado en dos roles: la investigación de nuevas formas de ciencia y la enseñanza de estas. Habían crecido ampliamente las expectativas respecto del futuro y no sobre la base de un autoengaño, sino sobre la base de respuestas tangibles y consideraciones concretas.

Con la descripción de la cultura que acabo de hacer en los párrafos precedentes, no es extraño constatar que la filosofía de fondo, la que se fue forjando en ese siglo XVIII pero que se consolidó en el XIX, fue el positivismo. Como diría Hegel, el positivismo fue "su época captada en pensamiento". Sin embargo, ¿qué significa positivismo?, es una pregunta con diferentes niveles de respuesta. Por un lado, y en términos más generales, positivismo es una crítica a la metafísica; esto es, es una crítica a los "castillos en el aire" - como definía Hermann Cohen a los argumentos metafísicos - que se construyen cuando pretendemos que hacer filosofía es igual a especular con la razón pura. Según el positivismo, los objetos de la investigación científica son aquellos concretos y "observables", justamente los objetos positivos - los negativos son los ídolos de la metafísica - que son con los que trata tanto el hombre de la calle como el científico. Hay que recordar que Augusto Comte inicia su argumentación afirmando la supremacía de la observación - como parte del método científico - por sobre la imaginación - propia de la metafísica - y así pretende afirmar la positividad del objeto de investigación científica.

En otro nivel de reflexión, positivismo significa la última etapa de desarrollo al que debe llegar la razón y la cultura. Después de haber superado las etapas previas - la religión y la metafísica - tanto el individuo como la sociedad alcanzan un nivel de madurez que lo lleva a pretender una real investigación sobre la naturaleza, en busca de su real comprensión, es decir, para controlarla y predecirla. El positivismo aquí se hace sinónimo no 
solo de madurez sino de trabajo científico (realista) de la naturaleza. Es interesante que aquí, Comte está identificando el desarrollo como una especie de destino ineludible tanto para el individuo como para la sociedad, una especie de evolución deseada y prefijada. También aquí aparece, junto al positivismo, la idea de progreso y desarrollo. Así por ejemplo, Simón Bolivar, quien fuera de clara tendencia positivista, alababa el orden y el grado de desarrollo al que estaba llegando Estados Unidos gracias a ser una sociedad forjada de la mano de la ciencia. El anhelo de Bolivar era pues formar "Los estados unidos del sur", una gran nación científicamente configurada.

En un tercer nivel de reflexión, positivismo significa monismo metodológico, es decir, la afirmación de que existe un solo método de acceso y comprensión de la naturaleza. Dicho único método es el método científico. Este puede ser entendido como iniciado por una hipótesis, sostenido por experimentos y concluido en una tesis comprobada. Muy unido a esto, además, la valoración del lenguaje matemático como el más apropiado - sino el único - para el desarrollo eficaz de la investigación científica. Durante el siglo XX, con el neo-positivismo, también se defendió esta idea del monismo metodológico y aún la necesidad y urgencia de unificar la ciencia. Algunos neo-positivistas incluso defendieron que la filosofía debía ligarse cada vez más a la ciencia hasta el punto de sostener la necesidad de una filosofía completamente científica (Reichenbach tituló a uno de sus libros TheRise of ScienticPhilosophy). En la filosofía analítica del siglo XX (posterior al neo-positivismo) y en el pragmatismo estadounidense se ha defendido la necesidad de naturalizar la filosofía o la epistemología y esa ha sido causa de que muchas veces se confunda a estas tendencias de la filosofía con el positivismo.

Ya he comenzado a hablar del neopositivismo del siglo XX, aunque es necesario distinguir las etapas de esta escuela de pensamiento. El positivismo propiamente dicho se formó en el siglo XIX, y tiene como a su principal representante a Augusto Comte. Sus antecesores son varios, pero quizá uno para resaltar es Pierre Simon Laplace, un matemático, físico y astrónomo de comienzos del siglo XIX, quien es recordado por dos anécdotas muy elocuentes. La primera es su referencia hipotética - que expresaba más bien una creencia positivista muy arraigada en él - a una inteligencia que fuera capaz de conocerlo todo. Para tal inteligencia - decía - "nada podría ser incierto; y el futuro, así como el pasado, estaría frente a sus ojos". Y es que Laplace era un ferviente creyente en el determinismo y en la explicación mecánica del universo. Si se conocen todas las leyes del universo y se logra formar una inteligencia capaz de "computar" todos esos datos, entonces nada será escondido a los ojos de dicha inteligencia. Estas afirmaciones nos llevan a la segunda anécdota. Se cuenta que luego de escribir su famoso tratado La exposición del sistema del mundo fue citado por Napoléon quien lo interrogó por qué no había incluido a Dios en dicha explicación; a lo que Laplace respondió: "jamás he necesitado dicha hipótesis". Así pues, determinismo y ateísmo (o agnosticismo o secularismo) son otros dos elementos que componen el positivismo. Para el neo-positivismo, en cambio, se puede reconocer que el principio básico que lo funda es el verificacionismo; es decir, la idea de que todo objeto de investigación científica debe ser verificable, si no directamente por lo menos deben poderse conocer las posibilidades de la verificación. El verificacionismo, sin embargo, fue uno de los principios 
más criticados en los neo-positivistas especialmente tras reconocer que la física eisteiniana se estaba haciendo cada vez más especulativas y que sus objetos de estudio eran cada vez menos verificables.

Desde distintas otras perspectivas se pueden resaltar diferentes componentes del positivismo que son también nucleares. Así por ejemplo, John Dewey argumentaba que el centro del positivismo estaba en su distinción tajante entre hechos y valores. Según esta distinción, a la ciencia le corresponde el trabajo con los hechos - los estados observables o contrastables de la naturaleza y que son de carácter objetivos - mientras que a la filosofía (y a la religión) le corresponde tratar con los valores del mundo - los estados subjetivos - a los que uno se enfrenta solo con especulación. John Dewey y muchos otros autores se han encargado de criticar este postulado central positivista. El argumento de John Dewey se centra en reconocer que los hechos no son tan seguros como aparentan y que los valores tampoco son tan subjetivos que se les quiere definir; lo que termina acercando ambos lados hacia un centro que ya no permite el dualismo.

Lo que hay que considerar, sin embargo, es que el positivismo, durante todo su desarrollo al interior de la filosofía, y aún en la mente de las personas de la calle, se volvió prácticamente sinónimo de materialismo y cientificismo. Por el primero, se puede reconocer el desprecio por lo espiritual y religioso, y el menosprecio de los filosófico. Es la defensa del mundo tal y como se experimenta, concreto y terminado. Muchas veces, se asume que las teorías de la evolución eran la final conclusión del materialismo, lo que llevó a que muchos evolucionistas entraran en discusiones religiosas que, obviamente, no era el centro de su argumentación. Por el cientificismo se entiende la sobrevaloración de la ciencia y sus posibilidades de éxito en la explicación, control y predicción de la naturaleza. Esta tendencia fue muy fuerte a final del siglo XIX y, sorprendentemente, ha vuelto a ser fuerte a final del siglo XX.

\section{La epistemología contemporánea: Karl Popper y Thomas Kuhn.}

La aparición de la mecánica quántica y de la teoría de la relatividad significó una gran crisis en la comprensión de la ciencia, pues no solo representaba el derrumbe de la teoría modelo - la mecánica de newton - sobre el cual se había desarrollado la ciencia, sino que además significaba el desmoronamiento de principios claves de este cientificismo decimonónico, justamente esas premisas positivistas que he comentado. Habría que considerar algunas de ellas, por ejemplo, el determinismo, la tridimensionalidad del espacio, la indestructibilidad del átomo, etc. La aparición de estas ciencias exigía una nueva comprensión de la ciencia, ya no bajo los parámetros positivistas, sino bajo nuevas consideraciones. El Círculo de Viena, un grupo de filósofos liderados por Rudolf Carnap estaban pretendiendo lograr esa nueva comprensión de la cultura intentando asumir exigencias de las nuevas disciplinas científicas. El problema, sin embargo es que dichos intentos de comprensión estaban todavía muy dependientes de principios positivistas, por ello mismo fueron conocidos como neo-positivistas.

La pregunta que nos podemos hacer es, sin embargo, ¿por qué el derrumbe de una teoría puede significar una crisis en la comprensión de toda la ciencia? La respuesta ya la adelanté. No se trata de cualquier teoría, sino de la teoría modelo. 
Si la ciencia se había considerado como la única forma de acceder a un conocimiento verdadero, objetivo y estable en el tiempo; es porque se consideraba que esas eran las características de la física de Newton. Al reconocer su falsedad, el interrogante que surgía era ¿qué pasa con todo el resto de la ciencia? ¿Cómo entender la verdad de la ciencia, si ahora debíamos considerar que las teorías científicas, por muy estables y verdaderas que parezcan, pueden terminar siendo falsas o, por lo menos, solo temporalmente verdaderas? Estas nuevas interrogantes cuestionaron a los epistemólogos del siglo XX, y las más significativas respuestas vinieron de dos de ellos: Karl Popper y Thomas Kuhn.

Karl Popper no era un positivista, aunque fue muy cercano al Círculo deViena. Asistió a una reunión del Círculo, aunque como confesaba le hubiera gustado ser invitado más veces. El argumento central de su Lógica de la investigación científica era más bien una crítica al positivismo. Popper pretendía criticar el verificacionismo de los neopositivistas, pues, atendiendo a lo que él consideraba como el principal problema de la epistemología, nada se puede verificar a partir de experimentos y datos de las experiencias. A esto lo denominó el problema de la inducción. De una experiencia no se puede afirmar nada de manera general. Sin embargo, reconoció que sí es posible decir algo con contundencia a partir de los datos de la experiencia. Lo que se puede decir no es una afirmación, pero sí una negación. Las experiencias pueden falsar una teoría, mas no verificarla. Así entendió Popper que el falsacionismo era la manera correcta de comprender el trabajo científico. El falsacionismo respondía el problema de la inducción, y al mismo tiempo, respondía también a otro problema clave de la epistemología. El falsacionsimo era una respuesta a la pregunta por el criterio demarcatorio.
Es decir, el falsacionismo nos brindaba la manera exacta de determinar qué teoría es científica y cuál no lo es. Si una teoría puede ser falsable, entonces es científica; pero si no se le puede falsar, entonces no es científica. Como muchos de sus intérpretes han reconocido, estas respuestas de Popper hacían coincidir sus respuestas epistemológicas a la respuesta de sus preocupaciones políticas. Como él mismo confesaba, su preocupación en el plano de la política era la existencia de esos gobiernos totalitarios. La superación de esos gobiernos totalitarios era afianzar más la discusión en la sociedad, lo que Popper llamó la sociedad abierta. Pues bien, el falsacionismo en epistemología significaba exactamente lo mismo que la sociedad abierta, es decir, reconocer el valor de la discusión como el método real de progreso en la ciencia. Lo que es discutible es entonces científico. A esta propuesta filosófica, Popper la denominó racionalismo crítico.

Thomas Kuhn fue más bien un físico, con afición a la filosofía y a la historia, y con fuerte influencia de la psicología de Jean Piaget. Kuhn intentó desprenderse plenamente del positivismo y atacó uno de los centros más neurálgicos de este: la relación científico-naturaleza. Para el positivismo, dicha relación aseguraba que el trabajo del científico sea exitoso y que se distinga plenamente de las otras formas de trabajo teórico (religión y filosofía). El positivismo, y el cientificismo en general, ve al científico como revelando a la naturaleza misma sin mediaciones de ningún tipo. Así pues, las teorías de la ciencia son verdaderas porque son una copia de lo que es la naturaleza misma. El trabajo de Kuhn incorporó en esa relación, entre el científico y la naturaleza, elementos sociológicos y psicológicos que terminaron haciéndola más compleja, pero al mismo tiempo más humana y más mediatizada. La sobrevaloración 
de la ciencia entraba en crisis, ya que la ciencia aparecía a los ojos de Kuhn como una institución solo diferente en grados respecto de otras instituciones de la cultura contemporánea. ¿Qué elementos introdujo Kuhn para explicar la ciencia? Principalmente dos: paradigmas y comunidades científicas. Estos dos elementos transformaron nuestra manera de ver al científico en su práctica diaria. Ya no se hablaba del científico, sino de comunidades de científicos. Y al interior de dichas comunidades, se entendían también elementos sociológicos y psicológicos. Se entendía que las comunidades funcionaban a partir de una confianza básica en su paradigma. No era una cuestión puramente racional, o por lo menos no racional en el sentido en que la Ilustración la había previsto. La racionalidad de la ciencia incorporaba ahora elementos sociológicos o también elementos psicológicos como la confianza. Si una comunidad pierde la confianza en su paradigma, esta comunidad puede entrar en crisis. Y aunque no lo dice Kuhn, hay que reconocer que todo paradigma siempre entra en crisis. La crisis es normal en tanto nada es eterno, ni las teorías científicas, ni los paradigmas. Lo que Kuhn reconoció es que dichas crisis no llegan tan fácilmente, sino que los científicos hacen todo lo posible para defender sus paradigmas. Ellos intentarán respuestas ad hoc antes de considerar que el paradigma ha fallado. Si se considera que el paradigma falló, entonces se acepta que esta falla es una anomalía del paradigma. Kuhn afirma que muchas explicaciones ad hoc y muchas anomalías aceptadas terminan por deformar el paradigma, y con ello comienza a perderse la confianza en él y la crisis es ya una realidad.

Si observamos bien, es esta justamente la diferencia entre Popper y Kuhn, mientras que Popper reconocía la discusión como lo propio del funcionamiento de la ciencia - decía Popper que la ciencia se mueve a punta de problemas - en cambio Kuhn reconocía la actitud de defensa del paradigma como la actitud propia de los científicos. Kuhn afirmaba que los científicos no pueden discutirlo todo, pues esa más bien es una actitud filosófica y no científica. Los científicos desarrollan su ciencia sobre la base de lo que ya se ha hecho. La discusión de la ciencia se desarrolla en revistas científicas que son por lo general en formato breve y para especialistas. Este formato de discusión supone no poner en tela de juicio toda la ciencia, sino que se trata de ir discutiendo poco a poco algo, pero ir defendiendo el paradigma o simplemente ir explicándolo. La epistemología contemporánea se ha nutrido enormemente con el aporte de estos dos pensadores, y quizá una complementación de ambos nos alumbre mejor lo que es la ciencia y su manera de institucionalizarse. 


\section{REFERENCIAS}

Agazi, E. (2011) La ciencia y el alma de occidente. Madrid: Tecnos.

Arendt, H. (1996) La condición humana. Barcelona: Paidós.

Bacon, F. (2011) La gran restauración. (Novum Organum). Madrid: Tecnos.

Chalmers, A. (2000) ¿Qué es esa cosa llamada ciencia? Madrid: Siglo XXI.

Comte, A. (1982) Discurso sobre el espíritu positivo. Buenos Aires: Aguilar.

Descartes, R. (2010) El discurso del método. Madrid: Mestas.

Dewey, J. (1952) La busca de la certeza. México: FCE.
Dewey, J. (1970) La reconstrucción de la filosofía. Buenos Aires: Aguilar.

Earls, J. (2013) Introducción a la teoría de los sistemas complejos. Lima: PUCP. Fondo Editorial.

Kant, I. (1988) La crítica de la razón pura. Madrid: Alfaguara.

Kuhn, T. (2004) La estructura de las revoluciones científicas. México: FCE.

Marías, J. (1964) Historia de la filosofía y la ciencia. Madrid: Guadarrama.

Popper, K. (1974) Conocimiento Objetivo. Un enfoque evolucionista. Madrid: Tecnos. 
